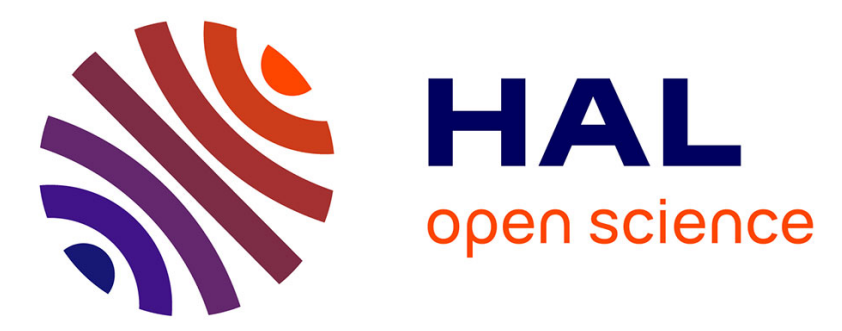

\title{
Microstructural observations supporting thermography measurements for short glass fibre thermoplastic composites under fatigue loading
}

Lucien Laiarinandrasana, Thilo F. Morgeneyer, Y. Cheng, L. Helfen, V. Le Saux, Yann Marco

\section{To cite this version:}

Lucien Laiarinandrasana, Thilo F. Morgeneyer, Y. Cheng, L. Helfen, V. Le Saux, et al.. Microstructural observations supporting thermography measurements for short glass fibre thermoplastic composites under fatigue loading. Continuum Mechanics and Thermodynamics, 2020, 32, pp.451-469. 10.1007/s00161-019-00748-4 . hal-02052685

\section{HAL Id: hal-02052685}

\section{https://hal-ensta-bretagne.archives-ouvertes.fr/hal-02052685}

Submitted on 27 Sep 2021

HAL is a multi-disciplinary open access archive for the deposit and dissemination of scientific research documents, whether they are published or not. The documents may come from teaching and research institutions in France or abroad, or from public or private research centers.
L'archive ouverte pluridisciplinaire HAL, est destinée au dépôt et à la diffusion de documents scientifiques de niveau recherche, publiés ou non, émanant des établissements d'enseignement et de recherche français ou étrangers, des laboratoires publics ou privés. 


\title{
Microstructural observations supporting thermography measurements for short glass fibre thermoplastic composites under fatigue loading
}

\author{
L. Laiarinandrasana - T. F. Morgeneyer - Y. Cheng • \\ L. Helfen · V. Le Saux · Y. Marco
}

\begin{abstract}
This paper combines the infrared thermography and the computed laminography techniques to better understand the mechanisms of damage under fatigue for a short fibre-reinforced thermoplastic material. Depending on the experimental technique used, the measurement implies a "homogenization" of the values deduced over a prescribed volume. The real volume contributing to the thermal fields and thus the dissipated energy evaluated from thermography cannot be easily determined. The laminography technique provides precious insights for the determination of the dissipation fields, by providing a clearer view of the in-depth notch front profile as well as the local fibre orientation and by giving an idea of the volume change induced by porosity. In turn, the latter may affect the physical (thermal) constants used in the determination of the dissipated energy.
\end{abstract}

Keywords Fatigue $\cdot$ Composites $\cdot$ Thermography $\cdot$ Tomography/laminography

L. Laiarinandrasana ( $\varangle)$. T. F. Morgeneyer Centre des Matériaux, CNRS UMR 7633, MINES ParisTech - PSL Research University, BP 87, 91003 Evry Cedex, France E-mail: lucien.laiarinandrasana@mines-paristech.fr

T. F. Morgeneyer

E-mail: thilo.morgeneyer@mines-paristech.fr

Y. Cheng $\cdot$ L. Helfen

European Synchrotron Radiation Facility (ESRF), BP 220, 38043 Grenoble Cedex, France

E-mail: yin.cheng@esrf.fr

L. Helfen

Karlsruhe Institute of Technology (KIT), Institute for Photon Science and Synchrotron Radiation (IPS),

76344 Eggenstein-Leopoldshafen, Germany

E-mail: lukas.helfen@kit.edu

V. Le Saux · Y. Marco

UMR CNRS 6027, IRDL, ENSTA Bretagne, 29200 Brest, France

E-mail: vincent.le_saux@ensta-bretagne.fr

Y. Marco

E-mail: yann.marco@ensta-bretagne.fr 


\section{Introduction}

One of the current major concerns of the transport industries is the capacity to produce lightweight structures without any compromise regarding their thermomechanical resistance. This becomes even more crucial for the automotive industry that wishes to reduce its $\mathrm{CO}_{2}$ emissions and fuel consumption to meet the new norms. Short glass fibres-reinforced thermoplastics are appropriate candidates because they combine good stiffness with an affordable cost due to the association of a low-cost material and the use of the injection moulding process that allows the manufacturing of complex part at high production rates.

Previously limited to non-structural parts, i.e. parts that did not have to withstand large loadings, they are now increasingly used in structural parts such as clutch pedals or engine mounts. Despite this increasing use, the design of such parts remains difficult for many reasons. The first is related to the complex shape of these parts, with the presence of stiffeners and ribs needed to circumvent the drop of rigidity compared to metallic solutions. These geometries lead to a complex local mechanical loading even if the macroscopic loading is uniaxial. These geometries thus induce complex mechanical gradients that need to be mastered in the design loop. The second is related to the heterogeneous nature of this kind of material with the presence of short fibres, usually glass fibres. These fibres lead to local stress concentrations in their vicinity, resulting in specific damage mechanisms such as debonding $[1,2]$. The interface between the fibres and the matrix is a critical area regarding fatigue since they induce stress concentration and a complex multiaxial loading [3]. The third reason comes from the complex fibre orientation induced by the injection moulding process that leads to anisotropy [4]. These orientation tensors remain very difficult to predict when the material is highly filled (usually, 35\% or 50\% by weight of fibres) [5]. Therefore, the design of structural reinforced thermoplastics requires a good understanding of the combination of the fibre orientation fields and the local mechanical fields and predictive models of local behaviour and failure.

In recent years, infrared thermography has proven its efficiency in evaluating the fatigue properties of materials [6] and even structures [7,8], by analysing the thermal fields during cyclic tests. The fatigue properties can be easily and quickly identified from 2D measurements. In parallel, computed tomography and computed laminography have developed rapidly to provide valuable information regarding microstructures and microscopic damage [2,9-11]. Three-dimensional damage has now become accessible, and the determination of damage kinetics possible from the appearance of the very first micro-cracks to the complete fracture of the specimen is now possible. However, infrared thermography and computed laminography have never as yet been compared on the same data set. In this paper, it is proposed to investigate specific complex configurations where the combined use of infrared thermography and laminography is employed to correlate 2D dissipation mappings obtained using infrared thermography with 3D damage information and fibres orientations obtained with laminography. The goal is to correlate the maximum dissipation area, evaluated from temperature mappings, with the maximum damage area evaluated from laminography.

This paper is divided into four sections. In Sect. 2, the material and specimens are detailed. Some information is given regarding the process, necessary for a good understanding of the complex microstructure. The structural samples have been obtained using inserts, generating a complex flow during the injection process, leading to complex fibre orientation. Specific terminologies describing the experimental data settings are introduced here: the stress concentration factors and the usage factors. In addition, the experimental set-ups used for the thermography measurements, as well as the laminography technique, are specified. Section 3 presents the results regarding several aspects (dissipated energy distribution and laminography results such as fibre orientation and deformed microstructures for the specimens studied). A discussion ends this section and achieves a comparison between the thermography and laminography results. Finally, a conclusion section summarizes the main results obtained.

\section{Materials and methods}

\subsection{Notched specimens}

\subsubsection{Material and characteristic dimensions of the specimens}

The material used in this study was a polyamide 66 (PA66) filled with $35 \mathrm{wt} \%$ of short glass fibres of $200 \mu \mathrm{m}$ length and $10 \mu \mathrm{m}$ diameter. The material had a glass transition temperature of $55^{\circ} \mathrm{C}$ in the dry state and $0{ }^{\circ} \mathrm{C}$ in the fully wet state [12]. 
The specimens considered in this study were plates (finite width $W=40 \mathrm{~mm}$ and thickness $e=3 \mathrm{~mm}$ ) presenting a central hole, obtained directly from the moulding process. The hole is considered as elliptical where $a$ and $b$ are the major and minor axes. For the particular case of circular hole, $a=b$.

As illustrated in the coordinates system in Fig. 1, the direction of loading has been considered as the longitudinal (direction 2), whereas directions (1) and (3) represent the width and thickness directions, respectively, throughout the paper. Two configurations were considered for the central hole:

- circular, where $b=a=5 \mathrm{~mm}$;

- ovaloid, i.e. a slot having semicircular ends with a radius $r=0.2 \mathrm{~mm}$. The ovaloid was assumed to be a narrow ellipse approaching a crack [13] for which $a=0.2 \mathrm{~mm}$ and $b=5 \mathrm{~mm}$.

\subsubsection{Reference stress concentration factors}

Considering a flat body made of a material exhibiting isotropic linear elastic behaviour, containing a defect (a hole), two stress concentration coefficients $\left(K_{\mathrm{tg}}, K_{\mathrm{tn}}\right)$ can be introduced [13]:

- The stress concentration coefficient based on the gross stress is

$$
K_{\mathrm{tg}}=\frac{\sigma_{\max }}{\sigma},
$$

where $\sigma_{\max }$ is the maximum stress at the edge of the hole and $\sigma$ the applied stress, distant from the hole;

- The stress concentration coefficient based on the net stress is

$$
K_{\mathrm{tn}}=\frac{\sigma_{\mathrm{max}}}{\sigma_{\text {net }}},
$$

where $\sigma_{\text {net }}$ is the net stress: $\sigma_{\text {net }}=\sigma /(1-a / W)$ where $a$ is the hole diameter and $W$ the width of the plate.

Although $K_{\text {tn }}$ is mostly recommended for fatigue problems, $K_{\text {tg }}$ values will be used in this work. This is because $K_{\text {tg }}$ takes two effects into account: i) stress concentration due to the loss of section; ii) stress concentration due to geometry. Moreover, from the relationship between $\sigma_{\text {net }}$ (Eq. 2) and $\sigma$ (Eq. 1), it is straightforward that

$$
K_{\mathrm{tn}}=K_{\mathrm{tg}}\left(1-\frac{a}{W}\right) .
$$

Actually, here $K_{\text {tg }}$ has been used as an indicator allowing the distinction of the two considered configurations. For the sake of simplicity throughout the paper, $K_{\mathrm{tg}}$ will be named as $K_{\mathrm{t}}$.

$K_{\mathrm{t}} \geq 1$ indicates the amplification of the stress around the defect. Its value depends on the geometry of the body (cylindrical or plate) and the geometry of the defect (elliptical or rectangular holes for instance). The notch root radius at the edge of the defect plays a significant role on the stress concentration induced. The smaller the notch root radius, the higher the stress concentration and the stress triaxiality. A commonly used formula for the stress concentration coefficient for an elliptic hole located in the centre of an infinite panel under tension can be expressed as follows [13-15]:

$$
K_{\mathrm{t}}=1+2 \frac{b}{a},
$$

where $2 a$ and $2 b$ are the principal axes of the ellipse, respectively; $b$ being the axis transverse to the applied tension $\sigma_{\text {net }}$. Equation 4 shows that for a centred circular hole, $a=b$ so that $K_{\mathrm{t}}=3$. Correction factors for finite width panel are proposed in Peterson's stress concentration factors [13], yielding $K_{\mathrm{t}}=2.5$ for the circular open hole.

In Fig. 1, the two considered specimens yielded the following $K_{\mathrm{t}}$ (actually $K_{\mathrm{tg}}$ ):

- circular hole, where $b=a=5 \mathrm{~mm}, K_{\mathrm{t}}=2.5$;

- ovaloid hole, assumed to be a narrow ellipse approaching a crack [13] for which $a=0.2 \mathrm{~mm}$ and $b=5$ mm. $K_{\mathrm{t}}$ was determined using Koiter's [15] table, yielding $K_{\mathrm{t}}=22.6$.

For the sake of simplicity, the two specimens were labelled as "Kt3" and "Kt20", respectively. Even if these geometries seem quite simple and classical, they are very interesting due to the strong anisotropic fibre orientation distribution. First, the location of the injection gate (bottom left of the plates, see Fig. 1) generates an asymmetric fibre arrangement along the length of the specimen within the $(1,2)$ plane. The orientation of the fibres also varied along the thickness (axis 3 ) due to the well-known "skin-core" effect induced by the fast cooling of the material on the mould surfaces during injection moulding that generates a strong orientation of the fibres along the viscous flow direction near the walls and a nearly orthogonal orientation at the core. More information is given in [16]. 
(a)

(b)

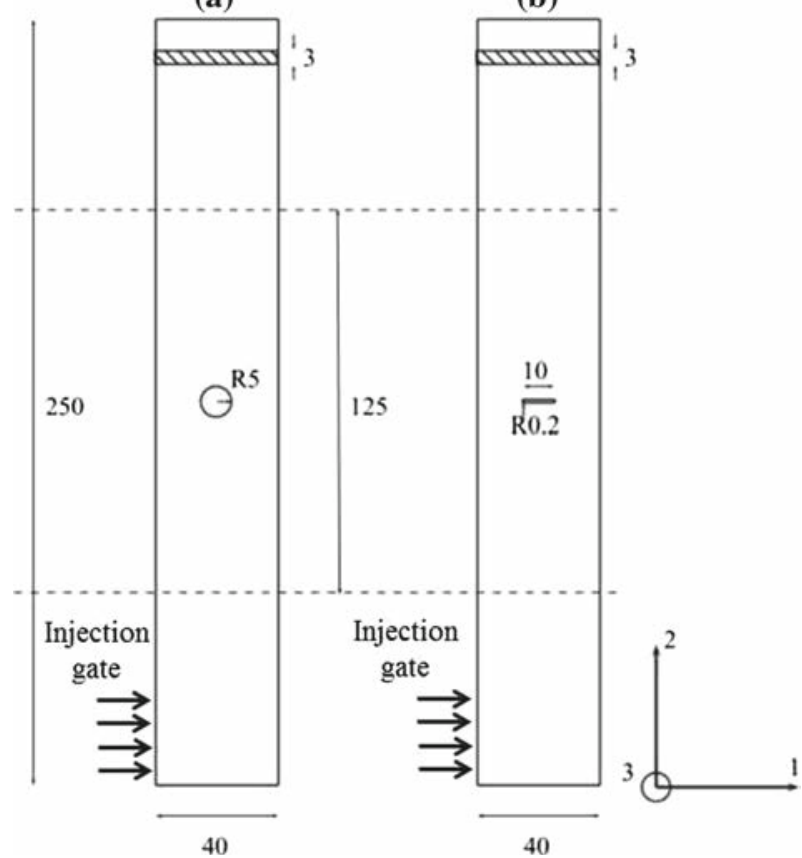

Fig. 1 Specimen geometry: panel containing central hole: a circular hole; $\mathbf{b}$ ovaloid hole $=$ slot having semi-circular ends. (All dimensions in $\mathrm{mm}$ )

\subsection{Experiments}

Theoretically, high values of $K_{\mathrm{t}}$ induce a higher stress level at the edges of the hole, thus promoting a decrease in the number of cycles to failure $N_{\mathrm{R}}$ for a given material when subjected to fatigue. For each $K_{\mathrm{t}}$ value, the Wöhler curve can be established using several gross stresses $\sigma$. Therefore, the $N_{\mathrm{R}}$ can be deduced for any applied load and $K_{\mathrm{t}}$. The usage factor $U_{\mathrm{f}}$ is introduced here as the actual number of cycles reached divided by $N_{\mathrm{R}}$ for a given couple $\left(K_{\mathrm{t}}, \sigma\right)$.

$$
U_{\mathrm{f}}=\frac{n}{N_{\mathrm{R}}} .
$$

The usage factor in Eq. 5, similar to the damage parameter in Miner's rule, equals 0 for a virgin material and takes the value of 1 when the specimen has reached $N_{\mathrm{R}}$. In the following, $U_{\mathrm{f}}$ will be considered as the degree of degradation of the sample.

In the vicinity of a crack front, the material experiences plasticity creating a plastic volume. The plastic zone defined in 2D within a plane parallel to the lateral surface depends on the location of this plane in the thickness. Accordingly, due to the effect of stress states in 3D (plane stress at the lateral surfaces and plane strain at mid-thickness) the plastic volume has the theoretical shape illustrated in Fig. 2. This plastic zone is based on the von Mises plasticity that does not account for the volume change due to cavitation. An attempt is made here to reveal experimentally the actual deformation of the matter ahead of the crack tip so as to better illustrate the shape of the plastic zone.

Each kind of specimen was subjected to fatigue tests, with controlled load at $1 \mathrm{~Hz}$ to avoid failure by thermal fatigue. Cyclic loads were imposed with a load ratio of $R_{\sigma}=0$. Three maximum loads were selected, and the number of cycles to failure was first determined for each of them. Then, for each maximum load, a specimen was submitted to 50 cycles, leading to various usage factor $\left(U_{\mathrm{f}}\right)$ values. Table 1 summarizes the experimental conditions for the six samples analysed.

\subsubsection{Thermography to speed up the determination of the fatigue curves}

Fatigue properties are usually evaluated by building a Wöhler curve. Each point of this curve is obtained by submitting a specimen of a given geometry to a given cyclic loading and measuring the number of cycles needed to reach an end-of-life criterion. This method presents at least two drawbacks. First, it requires a large 


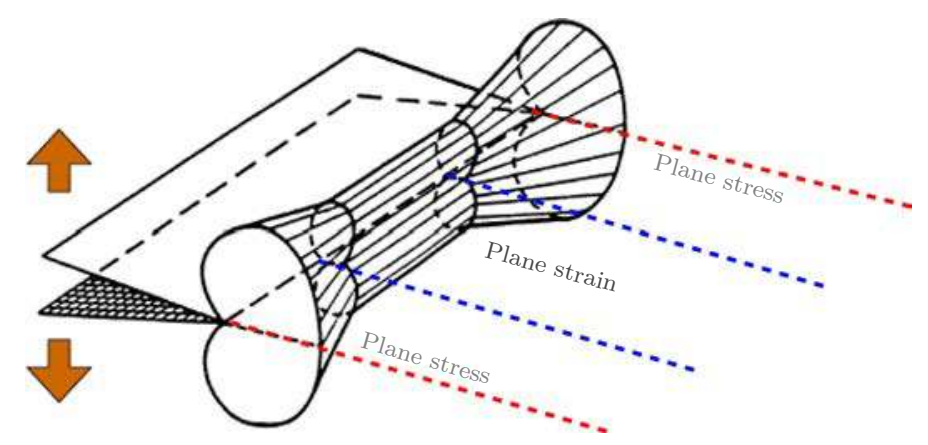

Fig. 2 Theoretical plastic volume in the vicinity of the crack front. The crack front is supposed to be straight, the plastic volume in Plane Stress (at the surface: red dashed lines) is three times larger than in Plane Strain (mid-thickness: between the blue dashed lines) (color figure online)

Table 1 Experimental testing parameters

\begin{tabular}{llll}
\hline$K_{\mathrm{t}}$ & $n^{\circ}$ & $N_{\mathrm{R}}$ & $U_{\mathrm{f}}$ \\
\hline 3 & 1 & $10^{6}$ & $5 \times 10^{-5}$ \\
& 2 & $5 \times 10^{5}$ & $10^{-4}$ \\
& 3 & 714 & $7 \times 10^{-2}$ \\
20 & 1 & $10^{6}$ & $5 \times 10^{-5}$ \\
& 2 & $5 \times 10^{5}$ & $10^{-4}$ \\
& 3 & 200 & 0.25 \\
\hline
\end{tabular}

number of specimens since fatigue is by essence a widely scattered process. Then, and this is even true for polymers, the loading frequency is chosen low enough to induce a minimal heat build-up, in such a way that no coupling to the temperature is induced. A direct consequence is the considerable time needed to build a Wöhler curve.

The last few years have seen the development of an alternative method for the estimation of the fatigue properties based on thermal measurements $[6,17]$. The basic idea of these methods consists in monitoring the surface temperature of a specimen in order to evaluate the intrinsic dissipation for various loading conditions and to relate these results to a Wöhler curve thanks to a fatigue criterion, assuming that the dissipated energy is a good indicator of the fatigue life. The main interest of this approach is its ability to provide reliable information, using fewer specimens, in less than one day, which is significantly shorter than a classical fatigue campaign. Moreover, the use of an infrared camera gives access to full-field measurements and thus provides valuable information on heterogeneous fields, such as the ones considered here.

The experiments have been carried out on an Instron hydraulic testing machine, and the thermal acquisitions have been made using a SC7600-BB Flir Systems infrared camera equipped with a 50-mm lens. The device has been calibrated using a compensated pixelwise calibration [18] in order to increase its thermal resolution. All the experiments were load controlled, and the samples cyclically loaded at a frequency of $1 \mathrm{~Hz}$ at a null load ratio $R_{\sigma}=\sigma_{\min } / \sigma_{\max }$. A contact extensometer was placed on the edge of the sample so as to record the notch opening displacement as a more local measurement. As the sample was to be submitted to increasing mechanical loading, the limited number of cycles applied for each loading conditions ( 20 cycles) prevented any severe damage from one loading stage to another.

\subsubsection{Synchrotron laminography}

Synchrotron radiation computed laminography (SRCL) is a non-destructive 3D X-ray imaging technique that allows for the assessment of the inner microstructure of laterally extended objects [19-21]. It overcomes the general limitation in CT measurement for which small cylindrical or dog-bone-shaped specimens are used because these small specimens are sometimes very different from standard mechanical tests and their plastic zones at the notch tips can be possibly larger than the specimen thickness, i.e. SRCL is compatible with realistic engineering boundary conditions.

Three-dimensional imaging of the Kt3 and Kt20 specimens was performed at the TopoTomo beamline [22] of the KARA storage ring (KIT, Karlsruhe, Germany). The inclination angle of the laminographic axis was 
chosen to be $25^{\circ}$. A filtered white X-ray beam with a photon energy window of approximately 10 to $24 \mathrm{keV}$ was used. The pco.dimax camera (PCO AG, Germany), which consists of a $2016 \times 2016$ pixels CMOS sensor with $12 \mu \mathrm{m} \times 12 \mu \mathrm{m}$ pixel size, was employed. It was coupled to an optical microscope [23] (Optique Peter, France) providing a $10 \times$ magnification with a numerical aperture $\mathrm{NA}=0.28$ which resulted in an effective pixel size of $1.2 \mu \mathrm{m}$, and a corresponding field of view of around $2.2 \times 2.2 \mathrm{~mm}^{2}$. Volumes were reconstructed from 2000 angularly equidistant radiographs using a filtered back-projection algorithm [24], with an exposure time of $\sim 20 \mathrm{~ms}$ for each projection (leading to a total scanning time of around $50 \mathrm{~s}$ for a single scan). The final reconstructed volumes had a size of $2016 \times 2016 \times 2016$ voxels. The voxel edge size was $1.2 \mu \mathrm{m}$.

\section{Results and discussion}

Experimental data are commonly based on macroscopic measurements at the surface of the tested specimen. Thermography falls within this kind of experimental technique. The contour map of the temperature is a signature of thermal activity at the surface, without a real knowledge in the thickness of the layer involved in this thermal signature. The laminography technique gives an insight using through-thickness measurements. The signature of the damage within the material can be mapped in 3D. This section attempts to report the results of both thermography and laminography techniques.

\subsection{Thermography}

Before showing the results, the basics allowing the determination of the dissipated energy mapping from surface thermal measurements are first recalled. Both quantities are related thanks to the heat equation that can be written, within the framework of the thermodynamics of irreversible processes [25], as:

$$
\rho c_{p} \dot{T}+\operatorname{div}(\mathbf{q})=\Delta_{\mathrm{int}}+r+\rho T \frac{\partial^{2} \Psi}{\partial V_{k} \partial T} \dot{V}_{k}+\rho T \frac{\partial^{2} \Psi}{\partial \boldsymbol{\varepsilon}_{\boldsymbol{e}} \partial T}: \dot{\boldsymbol{\varepsilon}}_{\boldsymbol{e}}
$$

where $c_{p}$ is the heat capacity, $\rho$ the density, $T$ the temperature, $\Delta_{\text {int }}$ the intrinsic dissipation, $r$ the external heat supply or loss, $\Psi$ the specific Helmholtz free energy, $\rho T \frac{\partial^{2} \Psi}{\partial V_{k} \partial T} \dot{V}_{k}$ the couplings of the internal variables between the anelastic mechanisms (viscoelasticity for instance) and the temperature, and $\rho T \frac{\partial^{2} \Psi}{\partial \varepsilon_{e} \partial T}: \dot{\varepsilon}_{e}$ the thermoelastic coupling.

In this equation, $T$ is directly measured using an infrared camera, giving access to a $2 \mathrm{D}$ temporal variation, and $\Delta_{\text {int }}$ is the investigated quantity, assumed to be a good indicator of the fatigue life. Equation (6) can be simplified using the following assumptions:

$-c_{p}$ is independent of the internal state;

- the convection term included in the material time derivative is neglected, i.e. $\dot{T}=\partial_{t} T$;

- the external heat supply is supposed to be constant during the test; thus, it vanishes when considering the temperature variation $\theta=T-T_{0}$;

- the thermoelastic coupling vanishes over one cycle.

Finally, by considering only the initial time, the diffusion phenomenon is assumed to be negligible. Therefore, Eq. (6) can be rewritten as follows:

$$
\rho c_{p} \dot{\tilde{\theta}}-\lambda \Delta \tilde{\theta}=\Delta_{\mathrm{int}}=f_{r} \Delta^{\star}
$$

More details such as temperature mappings have been reported elsewhere [7,26]. In Eq. (7), $\tilde{\theta}$ is the cyclic temperature variation evaluated considering two comparable mechanical loadings (e.g. when the stress is maximum), $f_{r}$ is the loading frequency, and $\Delta^{\star}$ is the intrinsic dissipation per cycle. The thermophysical parameters that are considered for the analysis of the data are given in Table 2.

The estimation of $\Delta^{\star}$ is usually achieved thanks to two different approaches. The first is based on the stabilized thermal state reached after a given length of time. The second is based on the initial temperature variations, assuming that the conditions for adiabaticity are met. The first is interesting because the thermal response depends on the dissipation over the whole volume. However, its resolution remains a challenge due to the ill-posed nature of the heat equation. The second is not affected by this difficulty, but remains a 2D view 
Table 2 Thermophysical parameters considered for the thermal analysis

\begin{tabular}{lc}
\hline Parameter $\left(\right.$ at $\left.23^{\circ} \mathrm{C}\right)$ & Value \\
\hline$\rho$ & $1390 \mathrm{~kg} / \mathrm{m}^{3}$ \\
$c_{p}$ & $1500 \mathrm{~J} / \mathrm{kg} / \mathrm{K}$ \\
$\lambda$ & $0.3 \mathrm{~W} / \mathrm{m} / \mathrm{K}$ \\
\hline
\end{tabular}
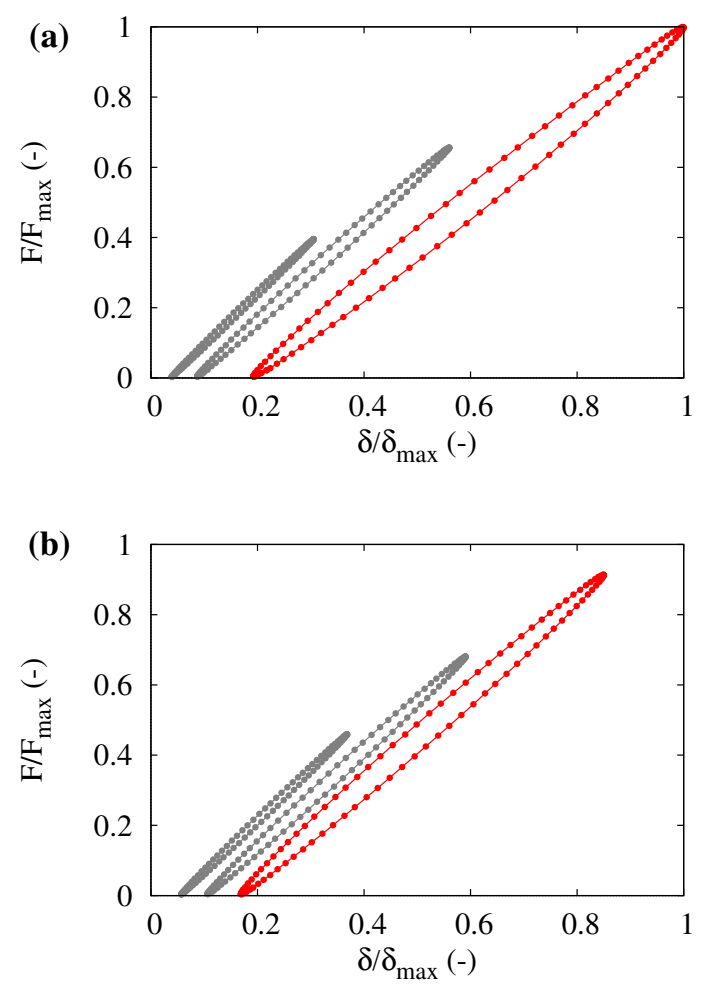

Fig. 3 Normalized load versus displacement (hysteresis loops) curves for all Kt specimens (increasing $U_{\mathrm{f}}$ from left to right): a for $\mathrm{Kt} 20$; b for $\mathrm{Kt} 3$

of a 3D sample. As mentioned in Sect. 3.3, the second approach was used to evaluate the dissipated energy. The exact way to compute $\Delta^{\star}$ is recalled:

$$
\Delta^{\star}=\left.\frac{\rho c_{p}}{f_{r}} \frac{\partial \tilde{\theta}}{\partial t}\right|_{t \rightarrow t_{0}} .
$$

For a given mechanical condition, the sample has been submitted to 20 cycles and the partial derivative is evaluated using cycles 2 and 1 using a finite difference approach.

Figure 3 shows the hysteresis loop at the end of the tests for the six couples of $\left(K_{\mathrm{t}}, U_{\mathrm{f}}\right)$. The mechanical responses in terms of normalized load versus displacement are plotted as shown in Fig. 3a, b for, respectively, Kt20 and Kt3 specimens. Note that these data corresponded to the 20th cycle. The following features were observed. The increase in the residual strain accompanied the increase in the load, thus $U_{\mathrm{f}}$. This reveals the overall viscoelastic-viscoplastic properties of the material. Additionally, the increase in the hysteresis loop was also observed in the same manner. This hysteresis loop could be associated with the cyclic dissipated energy. It should be underlined that the dissipated energy cannot usually be directly evaluated from the hysteresis loop without making a full energy balance [27]. However, it can be reasonably assumed that the trend remains the same, i.e. an increase in the hysteresis leads to an increase in the cyclically dissipated energy, leading to a reduction in the fatigue life.

The contour maps of the dissipation $\Delta^{\star}$ obtained from the measured temperatures for the two specimens and the three loading conditions are shown in Fig. 4. The heterogeneous nature of the $\Delta^{\star}$ fields could clearly 
Kt20

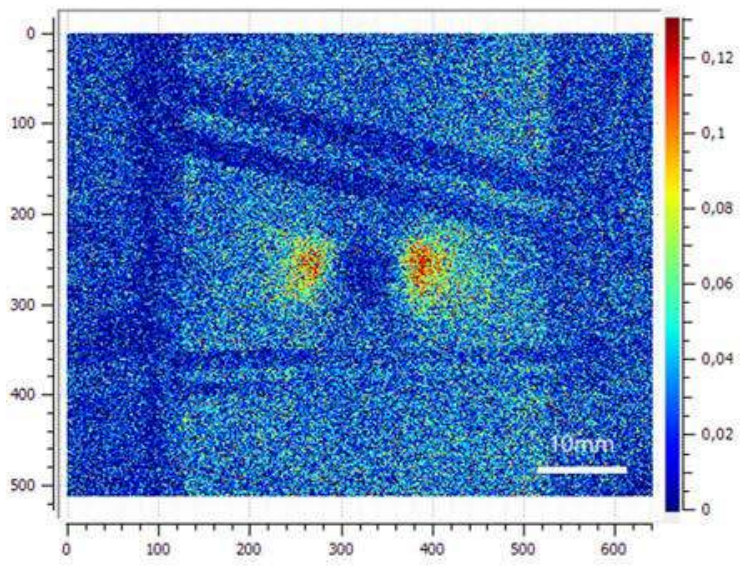

Kt3

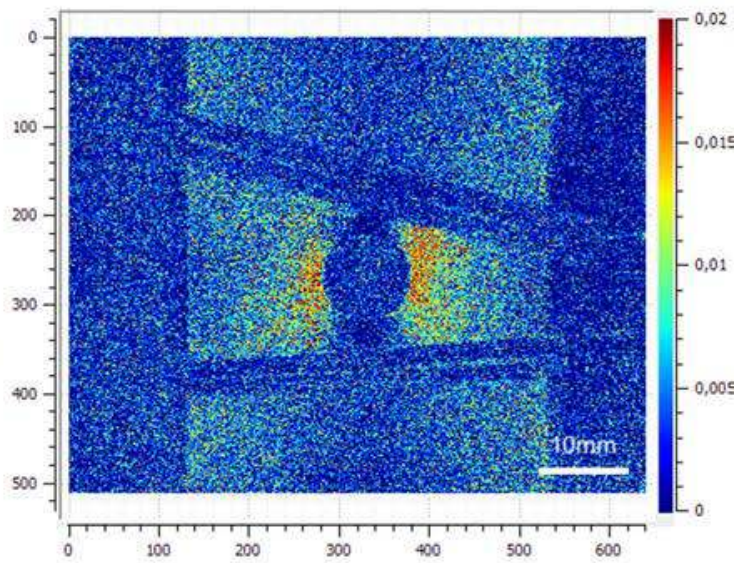

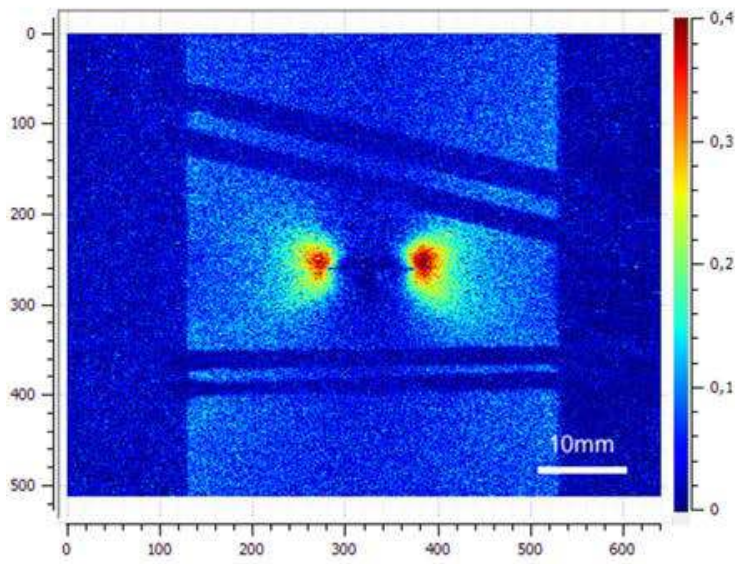
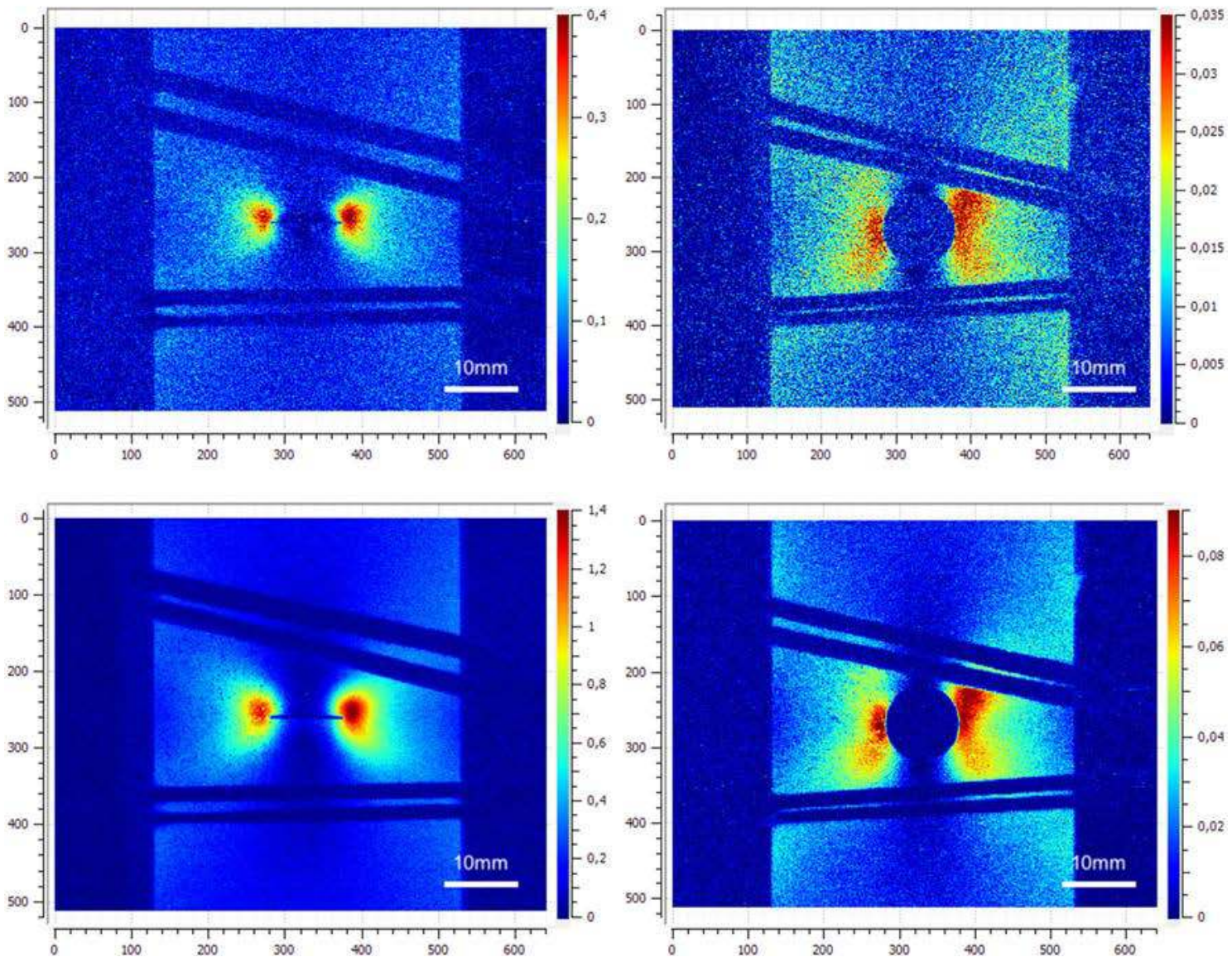

Fig. 4 Thermography results for all Kt specimens. Increasing $U_{\mathrm{f}}$ from top to bottom. Maximum $\Delta^{\star}$ (unit: $\mathrm{mJ} \mathrm{mm}^{-3}$ ) always located at a small distance from the notch tip

be highlighted. This can be attributed to the effect of the geometrical irregularity that leads to complex thermomechanical fields. Moreover, the fields were asymmetrically distributed due probably to the fibres orientation that was, as previously mentioned, disturbed by the presence of both the hole and the gate location on the one side of the specimen. The maximum dissipation depended on the considered specimen, but its location did not depend on the amplitude of the mechanical loading for a given specimen, which means that the failure location by fatigue was not dependent on the loading amplitude (for this load ratio at least). It should be underlined that the maximum dissipation was not directly located at the notch tip, but at a small distance ahead (a few 
hundreds of microns for the Kt20 specimen, close to $1 \mathrm{~mm}$ for the Kt3). For the tomography, it should be noted that the sample was observed in the unloaded state, some months after the experiment. This is likely to change the offset. The key point here is that this offset was clearly observed. At this stage, it was attributed to the skin effect related to the fast cooling of the matter at the free surface of the notch due to the mould. Based on these results, the critical areas for fatigue can be evaluated from these infrared measurements.

\subsection{Synchrotron laminography}

In this section, results from SRCL inspections with a $1.2 \mu \mathrm{m}$ resolution are discussed in terms of fibre orientation and of the location of the crack initiation point.

\subsubsection{Fibre orientation}

The injection gate was located at the side of the plate (Fig. 1). The flow of the molten matter during injection moulding process was oriented from the bottom to the top of the specimen. The flow front was forced to split around the insert creating the central open hole. Behind the insert, the two fronts merged again to generate a weld line. The effects of a cylindrical obstacle on the fibre orientation were thoroughly studied by Ayadi et al. [16] on undamaged material. It was pointed out that around the obstacle, the composite exhibited three layers through the thickness, instead of the "classical" skin-shell-core-shell-skin structure. Here, the less damaged specimens $\left(U_{\mathrm{f}}=5 \times 10^{-5}\right)$ were selected to track the variation in fibre orientation induced by the fabrication process. The general trends of fibre orientation were found to be still in line with that reported by Ayadi et al. [16] at this loading stage. To make easier the reading of the next figures representing 2D cuts from 3D data sets, in each figure, a sketch is systematically provided, to explain the "in-plane" or "out-of-plane" cuts. Features that are "in-plane" were observed with a side view, whereas "out-of-plane" configuration consisted of either a front view or a top view.

Figure 5 summarizes the main features observed for Kt3 specimen. As mentioned above, Fig. 5a indicates the location of the observed zones, the in-plane side view (red square), the out-of-plane front view (blue dashed square) and the vertical load direction. Figure $5 \mathrm{~b}$ shows the general trend of short fibres (in white) orientation parallel to the notch surface. The white dots correspond to the out-of-plane fibres. It can be seen that a layer of less than $100 \mu \mathrm{m}$ near the notch surface exhibited a higher concentration of the out-of-plane fibres. This observation is in agreement with that reported by Ayadi et al. [16]. To better illustrate the orientation of these out-of-plane fibres, Fig. 5c shows a front view close to the notch. In the vicinity of the notch boundaries, clusters of horizontal fibres can be noticed. A closer view similar to Fig. 5c is illustrated in Fig. 5d. Although this latter cut was extracted from another location, the clusters of fibres perpendicular to the load direction are also visible. A front view at a greater distance from the notch surface is shown in Fig. $4 d$ where the fibres are oriented in large part along the vertical load direction. It should be mentioned that

- the ring artefacts were not removed in these images: discernible in Fig. $5 b$ and clearly seen as black crosses in Fig. 5c, d;

- there are less out-of-plane fibres when moving down to the trailing edge.

The same analysis was carried out on Kt20 samples with $U_{\mathrm{f}}=5 \times 10^{-5}$ in Fig. 6 . The main stream of the melted flow is clearly shown by the orientation of the fibres in Fig. 6b. A closer look near the notch root is shown in Fig. 6c where the layer thickness of out-of-plane fibres decreases from the leading edge (top surface) to the trailing edge (bottom surface). The examinations of the front views for this sample led to the same conclusions as for Kt3 samples. Additional information is visible on the top view in Fig. 6d. In the left part of this figure, it can be observed that the fibres were "frozen" on the top surface, showing a random orientation. The same front view but located far from the notch front is illustrated in Fig. 6c. Here, a large part of short fibres follow the loading direction. It should be mentioned that the field of view did not allow the observation of the material surrounding the hole. The focus was put on where the maximum principal stress was expected to take place, i.e. side edge perpendicular to leading and trailing edges.

\subsubsection{Deformed microstructure for Kt20 samples}

To better highlight the microstructural evolution during the cyclic loading, the sample where the damage was expected to be a maximum was first selected . This specimen was a Kt20 sample with $U_{\mathrm{f}}=0.25$ as listed in 


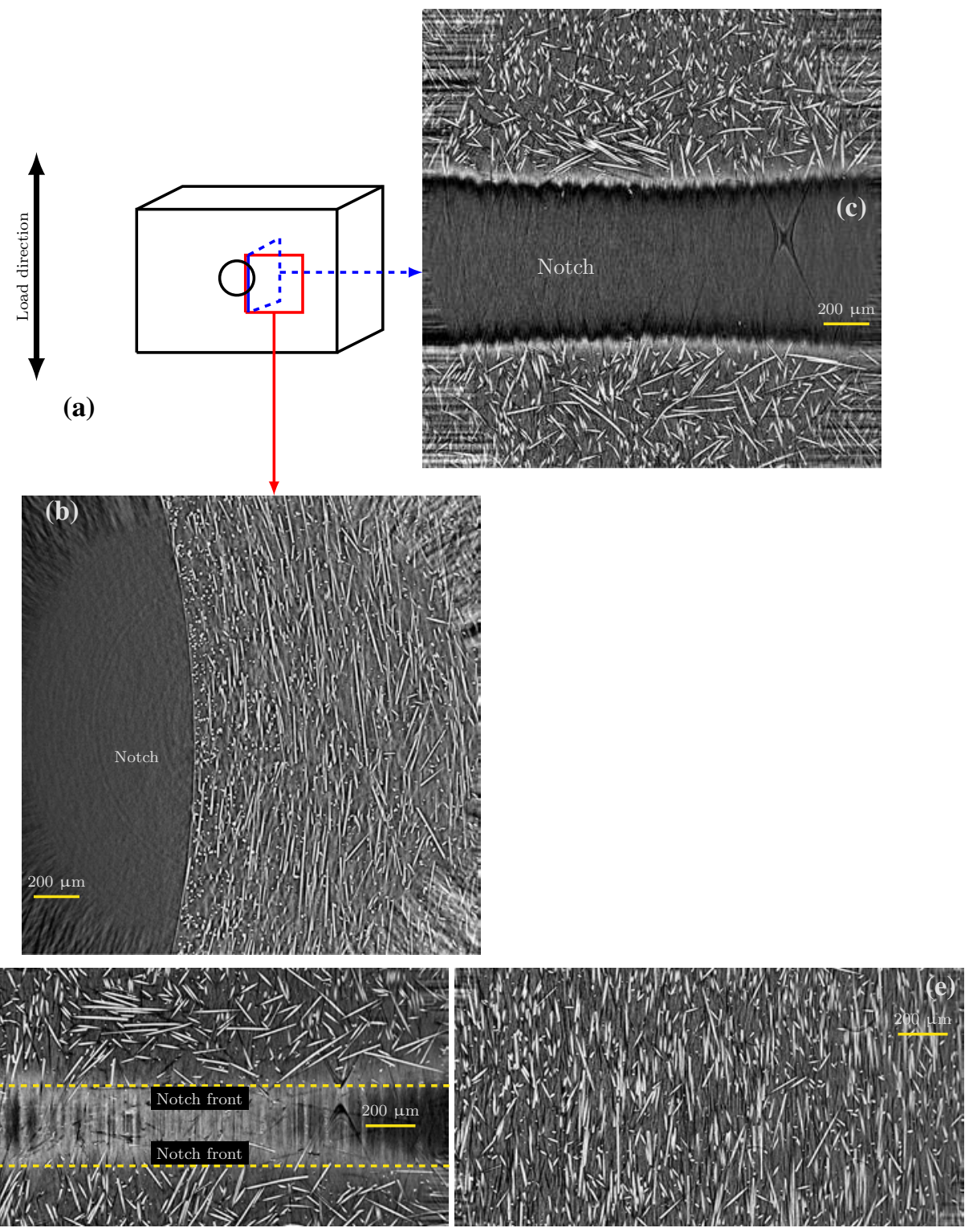

Fig. 5 Heterogeneity in the local orientation of the fibres due to the obstacle to set the notch for Kt 3 with $U_{\mathrm{f}}=5-10^{-5}$ : a sketch of the sample; $\mathbf{b}$ side view; $\mathbf{c}$ front view; $\mathbf{d}$ zoom of front view near the notch; e zoom of front view far from the notch

Table 1. In Fig. 7, two side views were extracted from the tomography data set. Figure 7a, b illustrates in-plane cuts near the lateral surface and at a depth corresponding to the mid-thickness plane, respectively. Both views highlight the morphology of the notch "tip" depending on the depth in the thickness. Indeed, the deformed notch tip ended with a straight vertical line, the height of which was greater near the surface (Fig. 7a) than at mid-thickness (Fig. 7b). Furthermore, as indicated by the arrows in the figures, the deformed notch was deeper by about $100 \mu \mathrm{m}$ in the thickness than near the surface. Two main conclusions may be drawn:

- the notch front was not straight in contrast to the theoretical consideration in the plastic zone (Fig. 2);

- the local notch root radius tended to infinity, implying a loss in the stress concentration factor.

In Fig. 7b, the presence of micro-cracks was clearly detected. In most cases, they were composed of a cluster of voids nucleating in the confined matrix between two out-of-plane fibres oriented perpendicularly to the load direction.

To better highlight these features, front views are shown in Fig. 8. The sketch in the left side of the figure indicates the four front views proposed. Since the crack front is curved, the notch is hidden by the matter when 

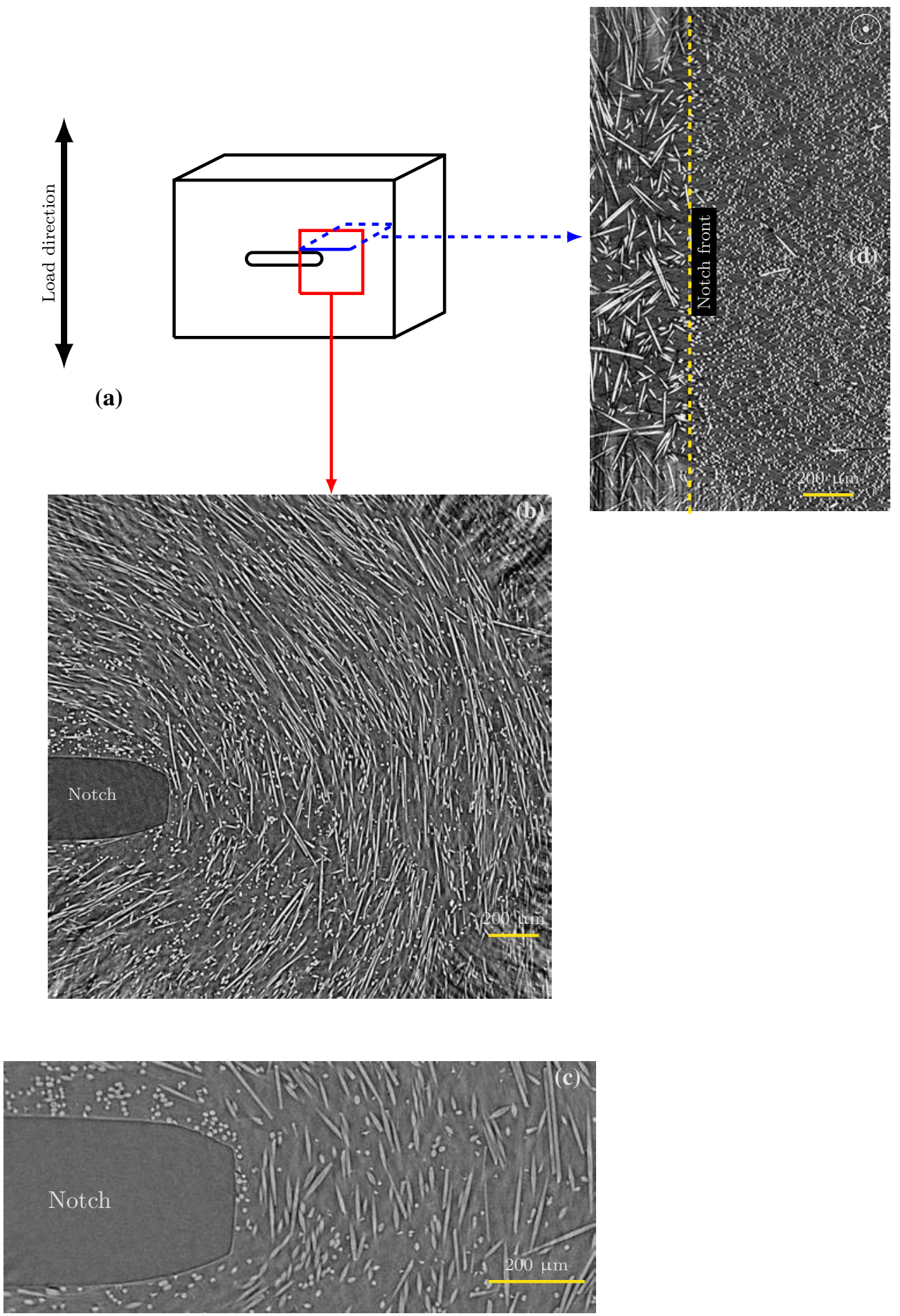

Fig. 6 Heterogeneity in the local orientation of the fibres due to the obstacle to set the notch for Kt20 with $U_{\mathrm{f}}=5 \times 10^{-5}$ : a sketch of the sample; $\mathbf{b}$ side view; c close view of (b); $\mathbf{d}$ top view

the front view is located deeper (further from the notch root). In all Fig. 8 front views, the lateral surface is to the right and the mid-thickness plane is located to the left part of the image. Attention has been paid to the matter located just in the vicinity of the notch tip, that is, on the left part of the views except for Fig. 8d. In Fig. 8a, a crack of about $150 \mu \mathrm{m}$ can be seen under an out-of-plane fibre, roughly perpendicular to the load 


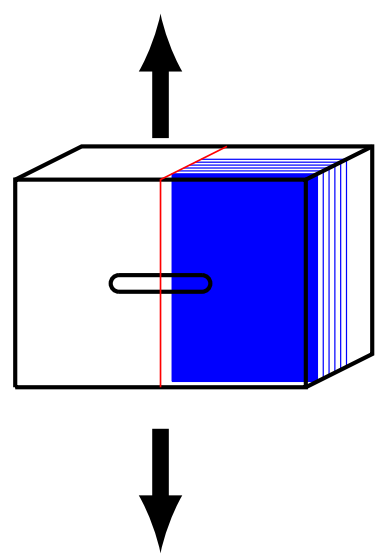

(a)

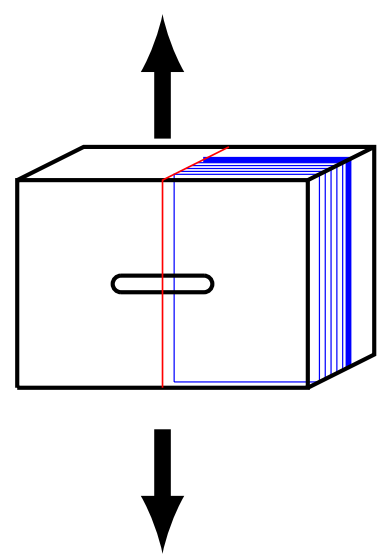

(b)
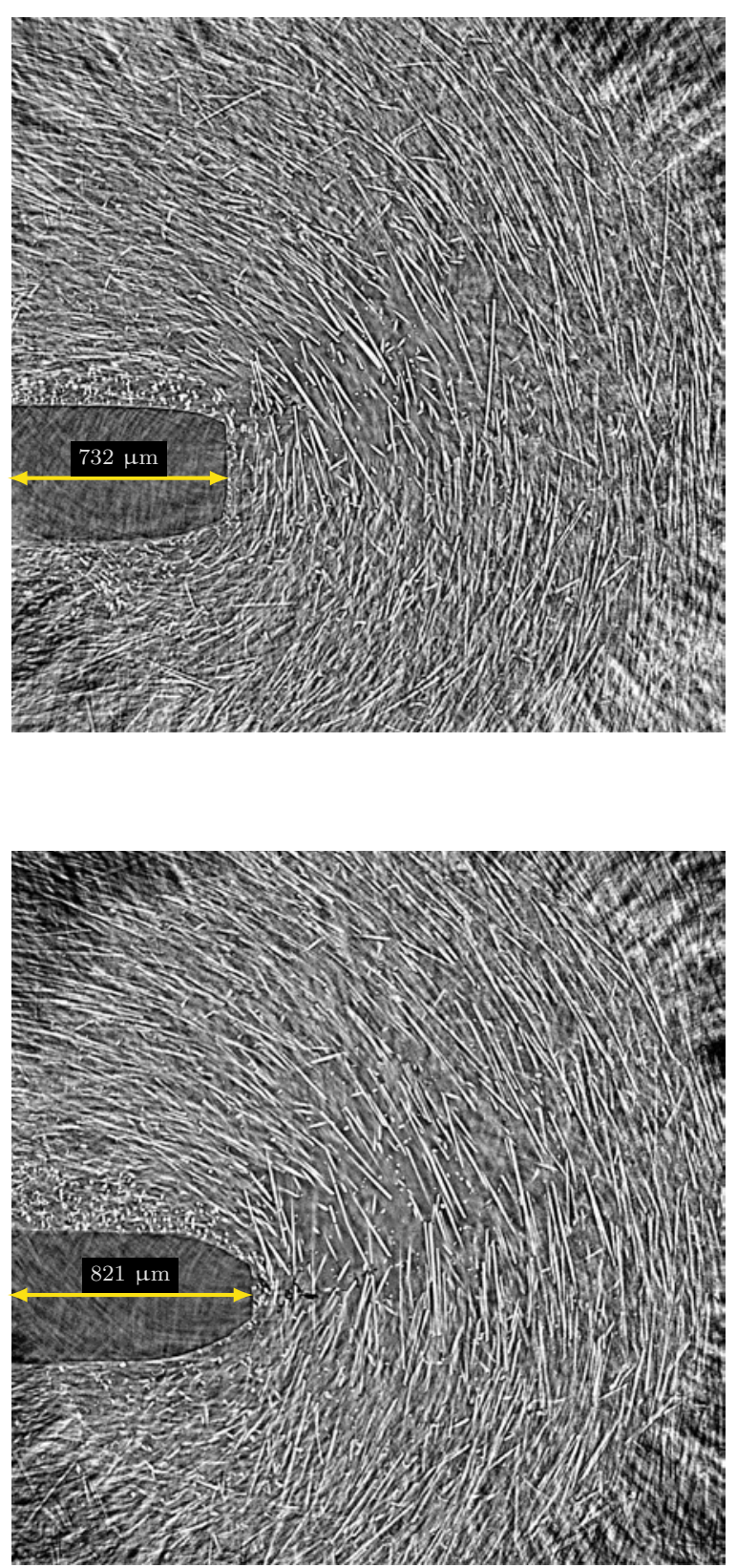

Fig. 7 Through-thickness notch root changes for Kt20 with $U_{\mathrm{f}}=0.25$, examinations at: a near the lateral surface; b plane around mid-thickness

direction. Moving $+8.7 \mu \mathrm{m}$ deeper, Fig. $8 \mathrm{~b}$ exhibits the same features although some voids due to breakage of fibres or nucleated at fibres' ends could also be observed $[2,16]$. Some fibrils parallel to the load direction could be examined within the micro-cracks. These seem to indicate a cohesive cracking, even if some debonding between the interfaces between the fibres and the matrix could be seen. This could also be confirmed when going deeper again $(+13 \mu \mathrm{m}$ from Fig. 8b). Voids and cracks were inspected within the matrix, always in the vicinity of out-of-plane fibres oriented perpendicular to the load direction in Fig. 8c. Further information was revealed and is shown in Fig. 8d where the micro-cracks ahead of the notch root were located at the mid-thickness (right part of the view). The crack length here was larger than in the other views. The overall orientation of the crack is perpendicular to the load direction. However, at the scale of the out-of-plane fibres, local oscillations could be observed, due to small mis-orientation with respect to the load direction. In addition, the left part of this front view shows clearly the strain of the matrix ahead of the notch tip. 


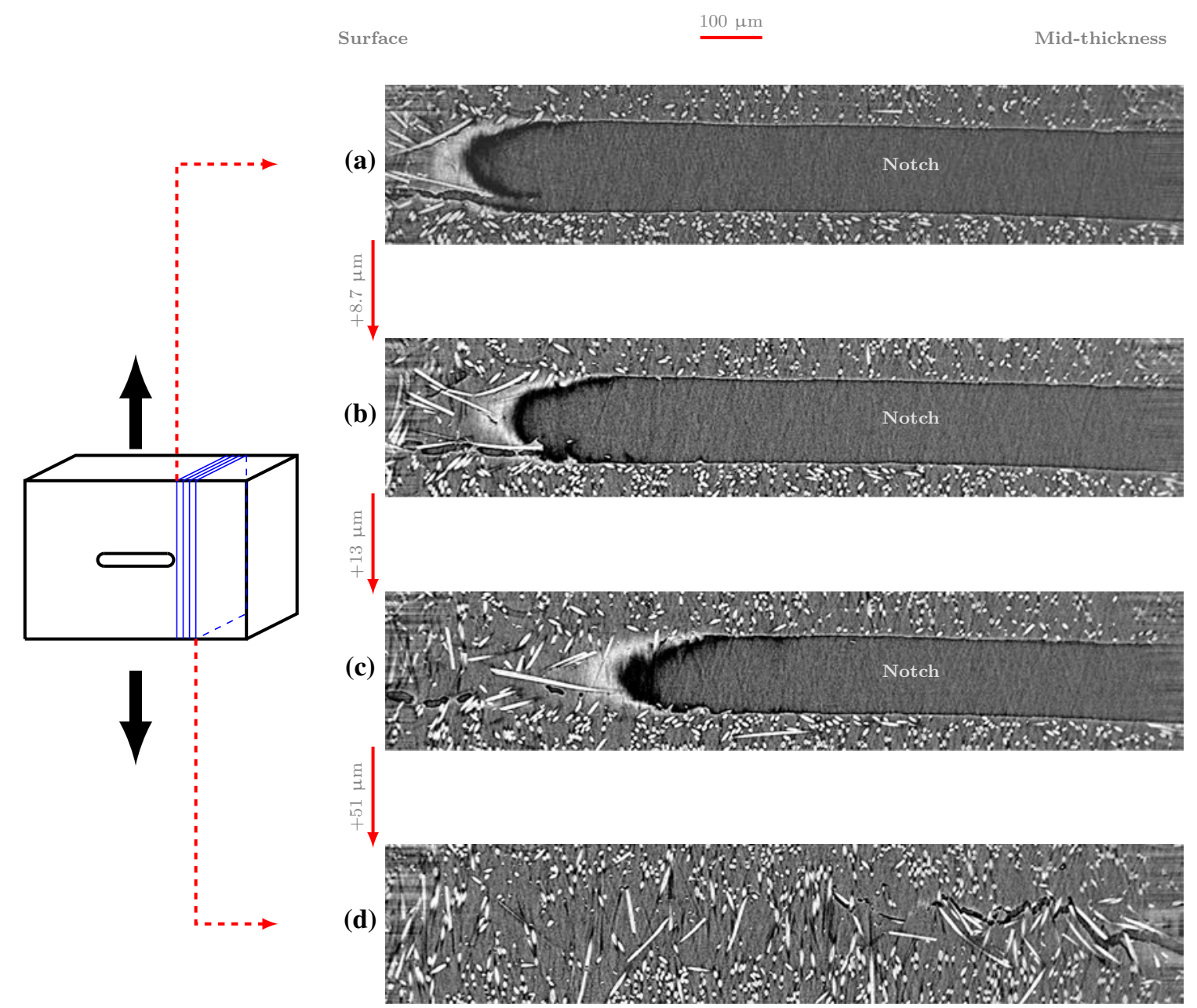

Fig. 8 Front views in the vicinity of the deformed notch root for Kt20 with $U_{\mathrm{f}}=0.25$. Four cuts were selected at increasing distance from the notch front: a close to the notch root at the lateral surface; $\mathbf{b}$ at $8 \mu \mathrm{m}$ away from cut (a); $\mathbf{c}$ at $12 \mu \mathrm{m}$ away from cut (b); d at $47 \mu \mathrm{m}$ away from cut (c)

Details of the deformation and damage are further illustrated in Fig. 9 which focuses on the notch root region at mid-thickness. The side view in Fig. 9a shows the reduced vertical straight line corresponding to the crack tip. The deformed notch root kept its "roundness" before this straight line. Voids near this notch tip were clearly initiated between the white dots characterizing the out-of-plane fibres. The size (especially the height) of these voids decreased when moving further away from the notch tip. The deformation due to the growth of these voids contributed to a large extent to the straight extension of the notch tip. In other words, by subtracting the height of the first big void in the vicinity of the notch root, the crack tip should have kept its "rounded" shape. The front view in Fig. 9b shows that the micro-cracks consist of coalesced voids. Black dots aligned above a fibre can be seen in the left part of Fig. 9b. Moreover, even when there is no surrounding fibres, voiding of the matrix shows the same observation of alignment of pores with a main orientation perpendicular to the load direction [11]. As already mentioned, local orientations of the crack following the direction of fibres contributed to the global orientation perpendicular to the load direction. Processing the data of fibres orientation should help to obtain the range of angles promoting void nucleation and growth.

Figure 10 shows an overview of the qualitative results from the inspections for the whole data sets. From the top to the bottom of the sub-figure, the images were taken from the surface to the region around mid-thickness. Likewise, from the left to the right part the side views presented correspond to increasing values of the usage factor $U_{\mathrm{f}}$. The text boxes included in the pictures indicate the depths in the thickness. The views dealing with the sample with $U_{\mathrm{f}}=0.25$ thoroughly discussed above were displayed in the right row. The presence of voids/micro-cracks can be seen whatever the depth in the thickness. The same trend can be observed for $U_{\mathrm{f}}=$ 


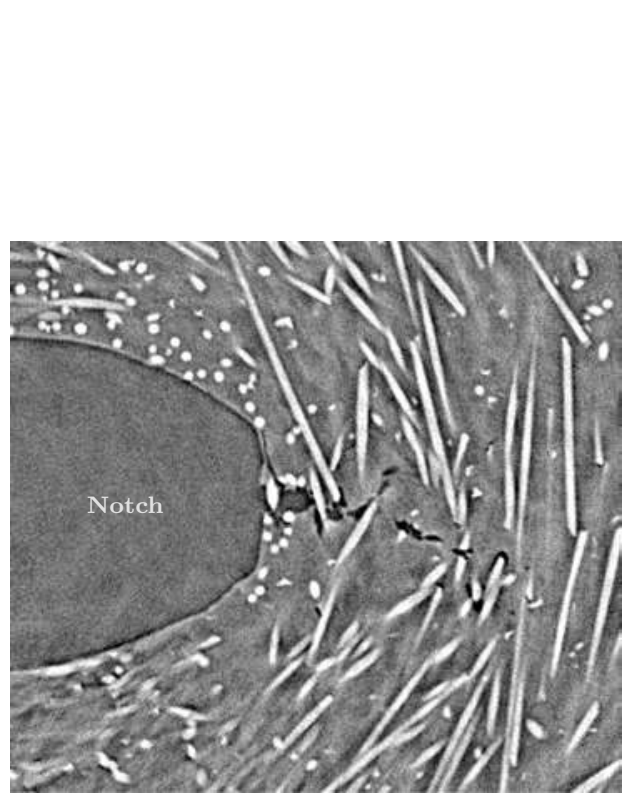

4

(a)

$100 \mu \mathrm{m}$

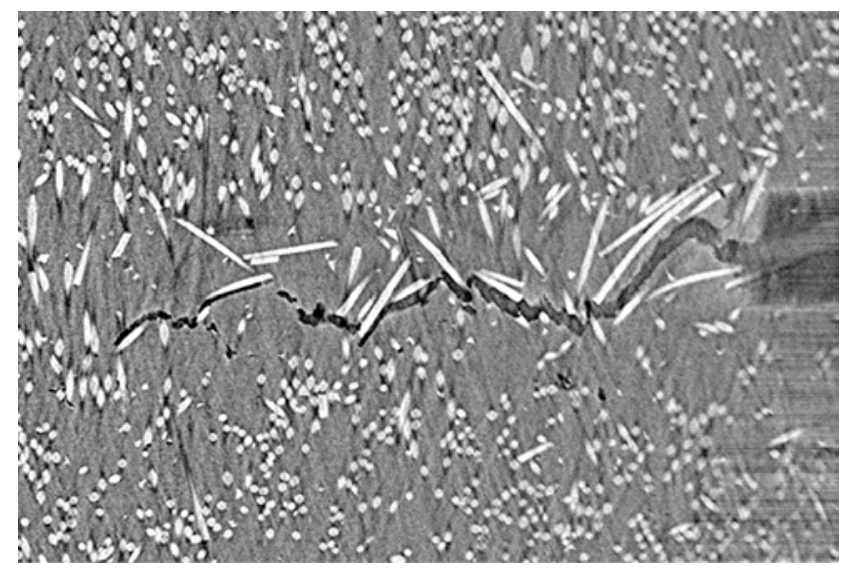

(b) $100 \mu \mathrm{m}$

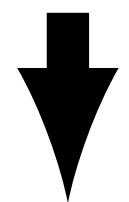

Fig. 9 Details of the crack orientation at the initiation: inter-fibre matrix perpendicular to the load direction: a side view; $\mathbf{b}$ front view ahead of the notch front. Arrows indicate the load direction

$10^{-4}$, but the damage is less developed at each configuration. For $U_{\mathrm{f}}=5 \times 10^{-5}$, damage could be detected only at mid-thickness. To summarize, voiding increased for increasing both usage factor and in-thickness depth.

Using commercial and public domain softwares (Avizo and ImageJ, respectively), an attempt has been made in Fig. 11 to quantify some of the observations reported above. Surface rendering in Fig. 11a highlights the morphology of the crack front. The crack depth change along this crack front, from the surface (left) to mid-thickness (right), is clearly seen. Moreover, the general trends consisted of: (i) more shallow cracks together with voids with smaller sizes near the surface; (ii) deeper cracks with bigger voids at mid-thickness; and (iii) very few voids in-between. To go further, two characteristic lengths were introduced to better analyse the shape of the crack front:

- the crack opening displacement $\delta_{\text {co }}$ is defined here as the height of the vertical straight line corresponding to the tip;

- the crack over-depth "a" is the distance between the crack tip and a baseline corresponding approximately to the crack opening displacement near the surface.

Figure $11 \mathrm{~b}$, c sketches $\delta_{\text {co }}$ and crack depth (a) measurements at two positions along the curved notch front. Full analysis of these two quantities was performed through the total inspected thickness by tomography (about $2.4 \mathrm{~mm}$ ). In Fig. 11d, the abscissa consists of the current thickness of the deformed specimen, normalized by $2.4 \mathrm{~mm}$. The origin ( 0 value) was attributed to the surface. It can be observed that the maximum over-depth (red full circles) is located at the maximum thickness. At this stage of $U_{\mathrm{f}}$, the deviation from the theoretical straight crack front as shown in Fig. 2 is less than $100 \mu \mathrm{m}$. The black full square symbols plot the evolution of $\delta_{\text {co }}$ along the crack front. In contrast to Fig. 2, there is no plateau corresponding to the stabilized plane strain assumption. The measurement indicates a continuous decrease from 0 to approximately 0.95 normalized thickness. One way in interpreting this result consists in considering the plate as being in-plane stress conditions on a large scale. The small part of matter located at mid-thickness exhibited an increase in $\delta_{\text {co }}$ (normalized thickness larger than 0.95 ). This is due to the above-mentioned extra-deformation attributed to void growth. Referring to Fig. 2 sketch, the plane strain condition is only restricted to a narrow zone at mid-thickness. Moreover, volumetric strain should be added to the theoretical Von Mises shear strain, allowing the definition of the plastic zone. 

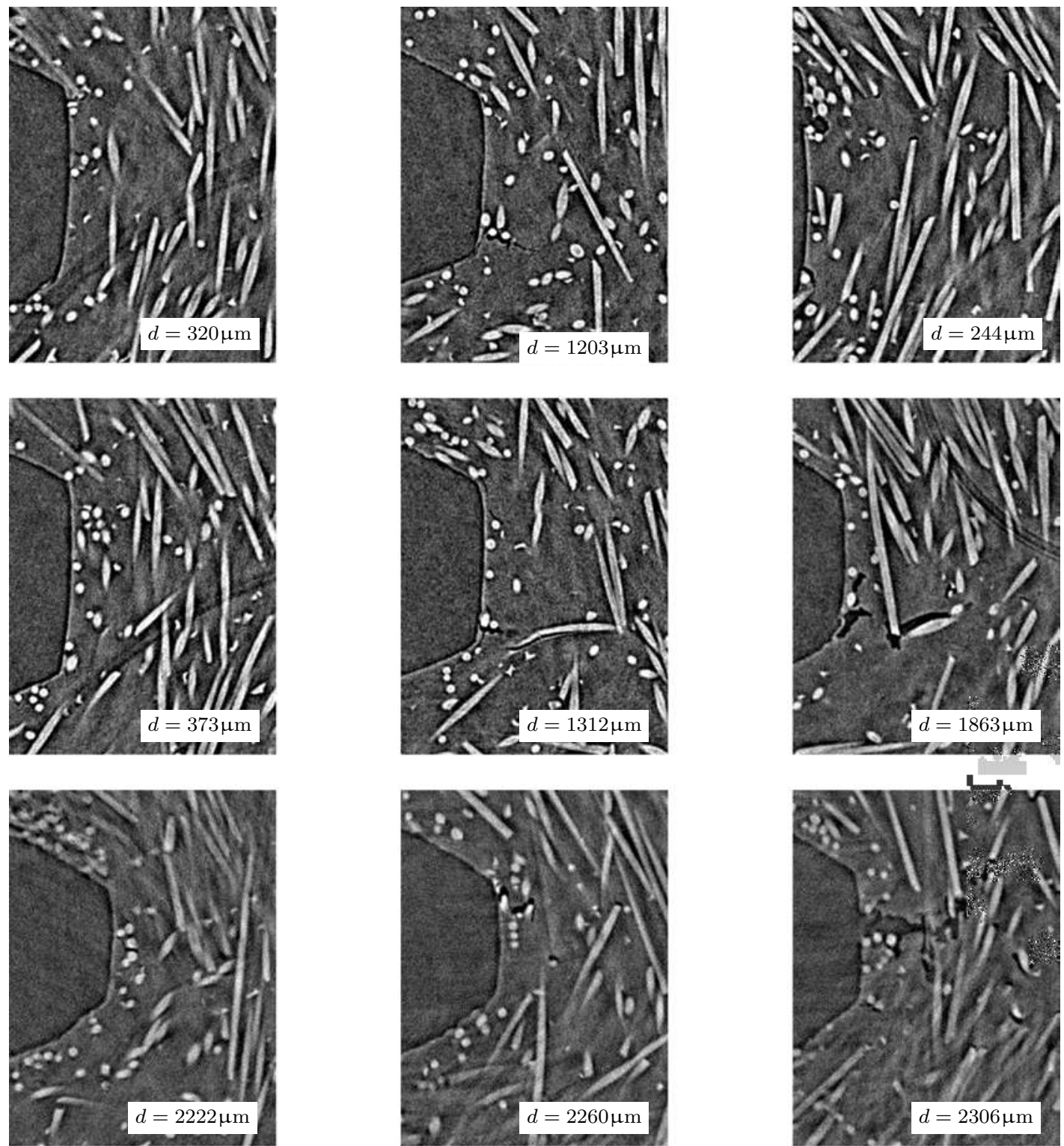

$\mathrm{U}_{\mathrm{f}}=10^{-4}$

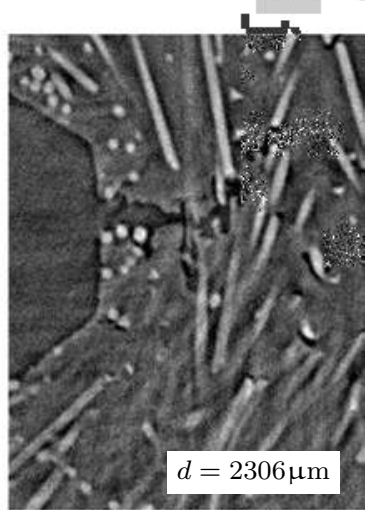

$\mathrm{U}_{\mathrm{f}}=0.25$

Fig. 10 Evolution of the microstructure ahead of the notch root for Kt20: for increasing $U_{\mathrm{f}}$ from left to right; for increasing depth (d) through the thickness from top to bottom

\subsubsection{Deformed microstructure for Kt3 samples}

As Fig. 10 summarizes the deformation and voiding in the vicinity of the notch front for Kt20 samples, this section deals with Kt3 deformed specimens (Fig. 12). For the highest value of $U_{\mathrm{f}}=0.07$, only a few voids could be found whatever the in-thickness depth. The most significant features were observed in the top right viewgraph, labelled $d=291 \mu \mathrm{m}$. Four mechanisms of void nucleation were examined as already reported by Rolland et al. [2] from uniaxial specimens submitted to fatigue:

- decohesion of the interface between matrix and out-of-plane fibres;

- decohesion of the interface between the matrix and fibre ends when these latter were parallel to the load direction; 


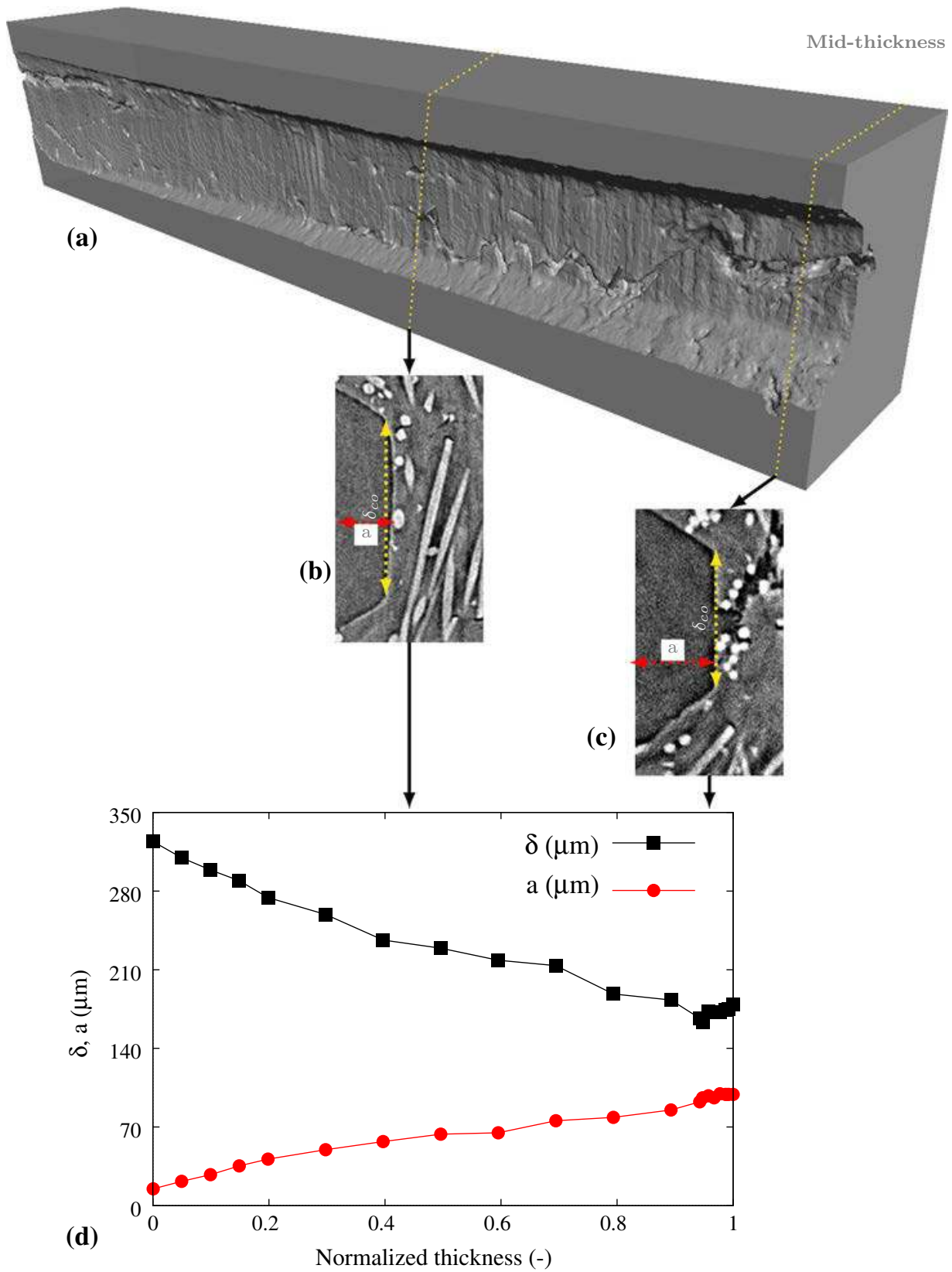

Fig. 11 Details of the notch root geometry and characteristic lengths: a surface rendering of the notch front; $\mathbf{b}$ side view at $1 / 4$ thickness; $\mathbf{c}$ side view at mid-thickness; $\mathbf{d}$ plots of the opening $\left(\delta_{\mathrm{co}}\right)$ and the depth (a)

- fibre breaks inducing void nucleation in the matrix;

- voiding of the matrix where the largest dimension corresponded to an orientation perpendicular to the load direction. This recalls penny-shaped voids occurring in the pure matrix [28-30].

As already shown in Fig. 3, lower values of $\Delta^{\star}$ were measured for these specimens. The laminography inspections show that actually, voids were of small size and more diffuse within the material. This can be attributed to the 10-mm-radius circular hole inducing less stress concentration than the ovaloid (notch root radius $0.25 \mathrm{~mm}$ ). Furthermore, the maximum of the out-of-plane fibre content was located in the leading edge (top of the hole), whereas the maximum stress and stress triaxiality were theoretically situated in the equatorial zone like the volume of interest here. The mechanical stress field did not meet the maximum confined matrix in this configuration. 

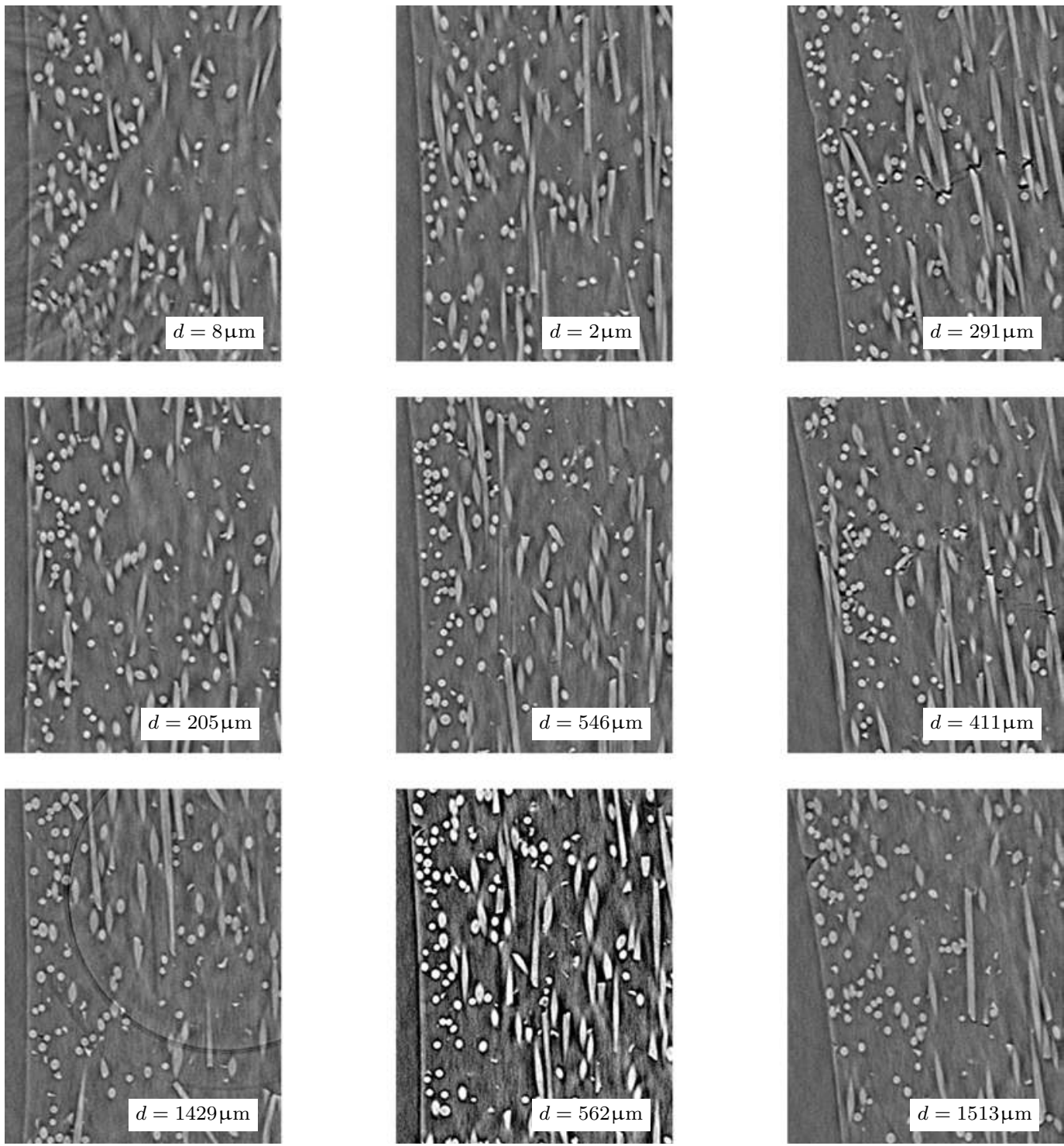

$\mathrm{U}_{\mathrm{f}}=5 \cdot 10^{-5}$

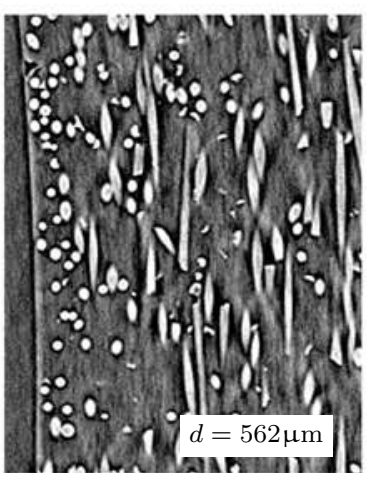

$\mathrm{U}_{\mathrm{f}}=10^{-4}$

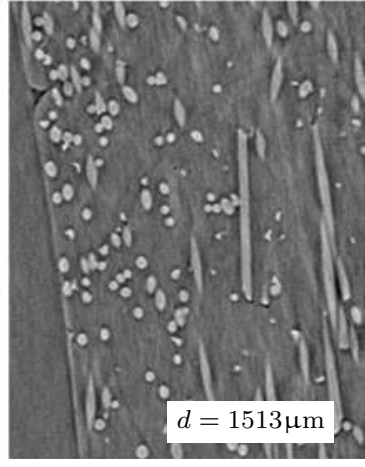

$\mathrm{U}_{\mathrm{f}}=0.07$

Fig. 12 Evolution of the microstructure ahead of the notch root for Kt3: for increasing $U_{\mathrm{f}}$ from left to right; for increasing depth (d) through the thickness from top to bottom

\subsection{Discussion: thermography versus tomography}

As illustrated by many studies $[6,7,26]$, the fatigue lifetime can be related to the fields of dissipated energy $\Delta^{\star}$. To generate these fields, the analysis is based on the thermal fields measured by an infrared camera. The relation between the surface temperature fields and the volumetric dissipation sources is not straightforward and requires several hypotheses, both on the spatial distribution and on the temporal evolution. The results presented in Sect. 3.1 were obtained using the hypotheses that the distribution of the dissipation sources was homogeneous over the thickness of the sample and that the thermal exchanges were limited, opening the way to an almost adiabatic case. Both hypotheses are of course disputable. First, the homogeneity of the dissipation sources is quite unlikely, taking into account the strong variation of the orientation tensor over the thickness. Second, conduction will always occur, even for these materials with a very low thermal conduction coefficient 
and even for a very short duration. Therefore, the evaluation of the dissipated energy from the surface temperature gives access to an average value of the dissipated energy, over a given volume. Using the physical parameters of the considered material (density, specific heat capacity, thermal conductivity), an analytical evaluation using basic thermal equations gives a characteristic distance of about $400 \mu \mathrm{m}$ for the characteristic time considered in the experiments ( $1.5 \mathrm{~s}$ between cycles 1 and 3 ). Nevertheless, for these heterogeneous case studies, the real volume contributing to the evaluation of the dissipated energy cannot be determined easily without numerical simulations or additional data. Moreover, various contributions to the total dissipation can be considered: viscoelasticity, (visco)plasticity and, of course, damage. The damage contribution as well as its role on the dissipation should be further analysed in depth. This is not in the scope of this paper. However, constitutive modelling, taking the damage mechanisms into account, should be a route to better understand the interaction between various sources of dissipation due to the stress concentration ahead of the notch root.

Laminography provides some further explanations. For instance, the dissipation fields evaluated for the Kt3 sample (see Fig. 4) showed that maximum dissipation was not located right at the edge of the notch but at a small distance (around $200 \mu \mathrm{m}$ ahead of the notch). At first sight, this distance can be related to two factors: the influence of the thermal exchanges at the free edge and the gradient in the orientation tensor at the skin of the edge. The data obtained from laminography offer another explanation as the measurements revealed that the notch front was curved. This change of geometry induced by the mechanical loading is very consistent with the thermal data as the distance from the initial straight notch is around $100 \mu \mathrm{m}$. This would suggest that this change of geometry occurring at mid-thickness is visible on the fields of dissipated energy measured on the surface.

Another contribution of laminography to the analysis of the thermographic results is related to a smaller scale than geometry variation, coming from the evaluation of the micro-porosity. The evaluation of this parameter is important for several reasons. Firstly, the specific mass and specific heat are of primary importance in the evaluation of the dissipation sources from thermal measurements. A gradient in these parameters, induced by micro-porosity, should be corrected and would possibly be measured with the laminography measurements. Second, the evaluation of micro-porosity gives access to the volume changes and provides a way of identifying the contribution of shear and volume changes in the global strain [30]. This is a very interesting way to split the contributions of shear, volume change and free surface creation from the overall dissipated energy measured.

\section{Conclusion}

The structural Kt specimens under study exhibited heterogeneity at multiple scales due to the geometrical irregularity associated with the holes. Fatigue tests were carried out on these specimens. Infrared thermography was used to quickly evaluate the fatigue properties of the composite material, by analysing the 2D thermal fields at the surface during several cycles. Well-controlled damage states using the usage factor $U_{\mathrm{f}}$ concept and fatigue-deformed specimens were inspected by laminography. Valuable 3D information regarding microstructures and microscopic cavities was made accessible. A better understanding of the damage mechanisms from the appearance of the very first micro-cavities at a resolution of $1.2 \mu \mathrm{m}$ was provided. This paper combines the analyses of the infrared thermography and the computed laminography results. It was shown that, depending on the experimental technique used, the measurement implies a "homogenization" of the values deduced over a prescribed volume. The real volume contributing to the thermal fields and thus the dissipated energy evaluated from thermography cannot be determined easily without numerical simulations or additional data. Moreover, the possible evolution of the physical constants induced by the damage is not accessible. The laminography technique provides here precious insights for the refinement of the dissipation fields, by providing a clearer view of the in-depth notch front profile as well as the local fibre orientation and by giving access to the volume change induced by porosity.

\section{References}

1. Horst, J.J., Spoormaker, J.L.: Fatigue fracture mechanisms and fractography of short glass fibre reinforced polyamide 6 . J. Mater. Sci. 32, 3641-3651 (1997)

2. Rolland, H., Saintier, N., Robert, G.: Damage mechanisms in short glass fibre reinforced thermoplastic during in situ microtomography tensile tests. Compos. Part B Eng. 90, 365-377 (2016)

3. Horst, J.J., Salienko, N.V., Spoormaker, J.L.: Fibre-matrix debonding stress analysis for short fibre-reinforced materials with matrix plasticity, finite element modelling and experimental verification. Compos. Part A 29, 525-531 (1998) 
4. Bernasconi, A., Conrado, E., Hine, P.: An experimental investigation of the combined influence of notch size and fiber orientation on the fatigue strength of a short glass fiber reinforced polyamide 6. Polym. Test. 47, 12-21 (2015)

5. Vincent, M., Griroud, T., CLarke, A., Eberhardt, C.: Description and modeling of fiber orientation in injection molding of fiber reinforced thermoplastics. Polymer 46, 6719-6725 (2005)

6. Jégou, L., Marco, Y., Le Saux, V., Calloch, S.: Fast prediction of the wohler curve from heat build-up measurements on short fiber reinforced thermoplastic. Int. J. Fatigue 47, 259-267 (2012)

7. Marco, Y., Le Saux, V., Jégou, L., Launay, A., Serrano, L., Raoult, I., Charrier, P.: Dissipation analysis of sfrp structural samples: thermomechanical analysis and comparison to numerical simulations. Int. J. Fatigue 67, 142-150 (2014)

8. Serrano, L., Marco, Y., Le Saux, V., Robert, G., Charrier, P.: Fast prediction of the fatigue behaviour of short-fiber-reinforced thermoplastics based on heat build-up measurements: application to heterogeneous cases. Contin. Mech. Thermodyn. 29, 525-531 (2017)

9. Bull, D.J., Spearing, S.M., Sinclair, I., Helfen, L.: Three-dimensional assessment of low velocity impact damage in particle toughened composite laminates using micro-focus x-ray computed tomography and synchrotron radiation laminography. Compos. Part A 52, 62-69 (2013)

10. Borstnar, G., Mavrogordato, M.N., Helfen, L., Sinclair, I., Spearing, S.M.: Interlaminar fracture micro-mechanisms in toughened carbon fibre reinforced plastics investigated via synchrotron radiation computed tomography and laminography. Compos. Part A 71, 176-183 (2015)

11. Cheng, Y., Laiarinandrasana, L., Helfen, L., Proudhon, H., Klinkova, O., Baumbach, T., Morgeneyer, T.F.: 3d damage micromechanisms in polyamide 6 ahead of a severe notch studied by in situ synchrotron laminography. Macromol. Chem. Phys. 217((5), 701-715 (2016)

12. Broudin, M., Le Gac, P.Y., Le Saux, V., Champy, C., Robert, G., Charrier, P., Marco, Y.: Water diffusivity in PA66: experimental characterization and modeling based on free volume theory. Eur. Polym. J. 67, 326-334 (2015)

13. Peterson, R.E.: Stress Concentration Factors. Wiley, New York (1974)

14. Inglis, C.E.: Stresses in a plate due to the presence of cracks and sharp corners. Engineering (London) 95, 415 (1913)

15. Koiter, W.T.: Note on the stress intensity factors for sheets strips with cracks under tensile loads. Report 314 of Laboratory of Engr. Mechanics, Technological University, Delft, Holland (1965)

16. Ayadi, A., Nouri, H., Guessasma, S., Roger, F.: Determination of orthotropic properties of glass fibre reinforced thermoplastics using X-ray tomography and multiscale finite element computation. Compos. Struct. 136, 635-649 (2016)

17. Doudard, C., Calloch, S., Hild, F., Cugy, P., Galtier, A.: Identification of scatter in high cycle fatigue from temperature measurements. Comptes Rendus Mécanique 10, 795-801 (2004)

18. Le Saux, V., Doudard, C.: Proposition of a compensated pixelwise calibration for photonic infrared cameras and comparison to classical calibration procedures: case of thermoelastic stress analysis. Infrared Phys. Technol. 80, 83-92 (2017)

19. Helfen, L., Baumbach, T., Mikulík, P., Kiel, D., Pernot, P., Cloetens, P., Baruchel, J.: High-resolution three-dimensional imaging of flat objects by synchrotron-radiation computed laminography. Appl. Phys. Lett. 86, 071915 (2005)

20. Helfen, L., Baumbach, T., Cloetens, P., Baruchel, J.: Phase-contrast and holographic computed laminography. Appl. Phys. Lett. 94, 104103 (2009)

21. Ueda, T., Helfen, L., Morgeneyer, T.F.: In-situ laminography study of three-dimensional individual void shape evolution at crack initiation and comparison with GTN-type simulations. Acta Mater. 78C, 254-270 (2014)

22. Rack, A., Weitkamp, T., Trabelsi, S.Bauer, Modregger, P., Cecilia, A., Rolo, T dos Santos, Rack, T., Haas, D., Simon, R., Heldele, R., Schulz, M., Mayzel, B., Danilewsky, A.N., Waterstradt, T., Diete, W., Riesemeier, H., Müller, B.R., Baumbach, T.: The micro-imaging station of the TopoTomo beamline at the ANKA synchrotron light source. Nucl. Instrum. Methods Phys. Res. Sect. B Beam Interactions Mater. Atoms 267(11), 1978-1988 (2009)

23. Douissard, P.A., Cecilia, A., Rochet, X., Chapel, X., Martin, T., van de Kamp, T., Helfen, L., Baumbach, T., Luquot, L., Xiao, X., Meinhardt, J., Rack, A.: A versatile indirect detector design for hard X-ray microimaging. J. Instrum. 7(09), P09016 (2012)

24. Myagotin, A., Voropaev, A., Helfen, L., Hänschke, D., Baumbach, T.: Efficient volume reconstruction for parallel-beam computed laminography by filtered backprojection on multi-core clusters. IEEE Trans. Image Process. 22, 5348-5361 (2013)

25. Lemaitre, J., Chaboche, J.L.: Mechanics of Solid Materials. Cambridge University Press, Cambridge (1990)

26. Masquelier, I., Marco, Y., Le Saux, V., Calloch, S., Charrier, P.: Determination of dissipated energy from temperature mappings on a rubber-like materials: experiments and comparison to numerical simulations. Mech. Mater. 80, 113-123 (2015)

27. Chrysochoos, A.: Thermomechanical analysis of the cyclic behavior of materials. Procedia IUTAM 4, 15-26 (2012)

28. Brusselle-Dupend, N., Rosenberg, E., Adrien, J.: Characterization of cavitation development while tensile testing PVF2 using 3D X-ray microtomography. J. Mater. Sci. Eng. A 530, 36-50 (2011)

29. Morgeneyer, T.F., Proudhon, H., Cloetens, P., Ludwig, W., Roirand, Q., Laiarinandrasana, L., Maire, E.: Nanovoid morphology and distribution in deformed hdpe studied by magnified synchrotron radiation holotomography. Polymer 55, 6439-6443 (2014)

30. Laiarinandrasana, L., Klinkova, O., Morgeneyer, T.F., Proudhon, H., Nguyen, F., Ludwig, W.: Three dimensional quantification of the anisotropic void evolution in deformed semi-crystalline polyamide 6. Int. J. Plast. 83, 19-36 (2016) 